\title{
Spatial and Temporal Variability of Aerosol Vertical Distribution Based on Lidar Observations: A Haze Case Study over Jinhua Basin
}

\author{
Wanchun Zhang, ${ }^{1,2}$ Mortier Augustin, ${ }^{3}$ Ying Zhang, ${ }^{1}$ Zhengqiang Li, ${ }^{1}$ Hua Xu, ${ }^{1}$ Dong Liu, ${ }^{4}$ \\ Zhenzhu Wang, ${ }^{4}$ Yuhuan Zhang, ${ }^{1,2}$ Yan Ma, ${ }^{1,2}$ Fengxia Zhang, ${ }^{1,2}$ and Yang $\mathrm{Lv}^{1,2}$ \\ ${ }^{1}$ State Environmental Protection Key Laboratory of Satellites Remote Sensing, Institute of Remote Sensing and \\ Digital Earth of Chinese Academy of Sciences, Beijing 100101, China \\ ${ }^{2}$ University of Chinese Academy of Sciences, Beijing 100049, China \\ ${ }^{3}$ Laboratoire d'Optique Atmosphérique, CNRS, UMR8518, Université Lille 1, 59655 Villeneuve d’Ascq, France \\ ${ }^{4}$ Key Laboratory of Atmospheric Composition and Optical Radiation, Anhui Institute of Optics and Fine Mechanics, \\ Chinese Academy of Sciences, Hefei, Anhui 230031, China \\ Correspondence should be addressed to Zhengqiang Li; lizq@radi.ac.cn
}

Received 4 July 2014; Revised 17 September 2014; Accepted 19 September 2014

Academic Editor: Bala Subrahamanyam

Copyright (C) 2015 Wanchun Zhang et al. This is an open access article distributed under the Creative Commons Attribution License, which permits unrestricted use, distribution, and reproduction in any medium, provided the original work is properly cited.

The impacts of haze emphasized significance of hazards for human activities and importance of observations of aerosol vertical distribution. This study aimed to analyze the aerosol vertical distribution during a haze case at temporal and spatial aspects, using space-borne and ground-based Lidar observations over Jinhua Basin, Zhejiang province, as well as the Hybrid Single-Particle Lagrangian Integrated Trajectory (HSPLIT) model and optical situ monitoring at Jinhua site. The results highlight three pollution peaks above the surface located in the upper and lower boundary layer in Jinhua Basin. The trajectory analysis shows the pollutants inside and outside the planetary boundary layer from different sources. Planetary boundary layer height (PBLH) obtained from the space-borne Lidar observations was compared with that from ground-based Lidar observations. The absolute error between the two instruments is about $0.193 \mathrm{~km}$. It is illustrated that the space-borne Lidar is an effective instrument for obtaining regional aerosol pollution in vertical section. Pollution transport near the ground is closely related with the terrain condition.

\section{Introduction}

Aerosol particles are a main component of the atmosphere and act as cloud condensation nuclei and for this reason influence cloud properties [1]. According to the findings of the IPCC [2], the current level of scientific understanding of the impact of aerosols on the global climate system is considered as medium to low. The effects of atmospheric aerosol particles depend on the spatial and vertical distribution of aerosols, their optical and microphysical properties, and the reflectance of the underlying surface and the presence of clouds [3].
In recent years, the haze pollution has drawn growing worldwide concerns, especially in developing countries [4]. The increasing of air pollution these years highlights the urgent need of an efficient monitoring of pollution atmospheric particles, which remains a difficult task due to high aerosol inhomogeneities in time and space [5]. However, ground-based Lidar can show atmospheric temporal variation (at a fixed location), while spaceborne Lidar can obtain atmospheric variation in space (in large-scale region). From Lidar data, we can get planetary boundary layer (PBL). And the planetary boundary layer is an important parameter to analyze the aerosol particles vertical distribution. The PBL 
is the closer turbulent layer closest to the Earth's surface. Its height, which can vary mainly from 1 to $2 \mathrm{~km}$ at midday, is crucial to many aspects of weather and climate [6].

Multiple approaches are used to determine PBLH and often give different results [7], such as model products, radiosondes, and Lidar technique. The use of modern groundbased Lidar techniques to follow the diurnal variations of the PBLH seems promising [8]. However, ground-based Lidars can only show atmospheric temporal variation. The CloudAerosol Lidar and Infrared Pathfinder Satellite Observations (CALIPSO) satellite has the potential to expand the available data tremendously. It can follow the regional variations of the atmospheric layering nearly at the same time. This study aims to analyze the aerosol vertical distribution during a haze case. The vertical distribution of the total attenuated backscatter coefficient profiles analysis is in the case depending on visibility level. Sections of this paper are organized as follows. Data and methods are presented in Section 2, the aerosol distribution analysis of a haze day is described in Section 3, and half a year of PBLH data observed in situ are used for discussion in Section 4, respectively. Summary and concluding remarks are given in Section 5.

\section{Data and Method}

2.1. Data and Instrument. CALIPSO carries the Cloud-Aerosol Lidar with Orthogonal Polarization (CALIOP) instrument, which can measure the vertical structure of the atmosphere at three channels. Two of these channels, at $532 \mathrm{~nm}$, are orthogonally polarized and one channel measures the total backscattered signal at $1064 \mathrm{~nm}$. CALIOP has a spatial resolution of $333 \mathrm{~m}$ along the orbital path. The satellite repeat cycle is 16 days [9]. The total attenuated backscatter coefficient profiles in CALIOP Level 1 and AOD, cloud layer in Level 2 have been used in this study.

The characteristics of the ground-based Lidar used in this study are similar to CALIOP ones with two orthogonally polarized channels at $532 \mathrm{~nm}$ and one channel at $1064 \mathrm{~nm}$. The Lidar was set at Zhejiang Normal University in Jinhua. The site altitude is $71 \mathrm{~m}$. The observations extend from May 2013 up to now.

2.2. PBLH Method from Lidar Observation. The PBL height is estimated using the attenuated backscatter coefficient. It is important to keep in mind that this is not a traditional, meteorologically based definition. The traditional definition uses temperature profiles from radiosondes to estimate the extent of turbulence by identifying the overlying inversion. This method identifies the aerosol-rich layer or the boundary layer capping clouds to estimate the extent of turbulence [10].

There are three methods which can be used to obtain PBLH from Lidar observation: a gradient technique, the Haar wavelet technique, and a maximum variance technique [11]. In this paper, we considered the Haar wavelet technique and a maximum variance technique comprehensively. The maximum variance technique developed by Jordan et al. [11] is used here to derive estimates of PBLH from CALIOP attenuated backscatter coefficient at wavelength of $532 \mathrm{~nm}$.
This method was used to analyze global seasonal variations of planetary boundary layer by McGrath-Spangler and Denning in $2012[6,12]$. This technique is based on an idea by Melfi et al. [10] and relies on the existence of a strong aerosols concentration gradient at the top of the $\mathrm{PBL}$, which can be detected by looking for the maximum in the vertical standard deviation of Lidar backscatter. This maximum in the standard deviation exists because within the entrainment zone, in clear conditions, turbulent boundary layer eddy mixes aerosol laden air with cleaner free tropospheric air. This mixture of clear and dirty air produces a large standard deviation in the backscatter [11]. In conditions with boundary layer clouds, a maximum in the standard deviation occurs either within or just above the cloud, depending on the specific conditions. The difference in estimates depends on the thickness of the cloud [6].

The algorithm has several limitations that must be considered. First, optically thick clouds or aerosol layers attenuate the signal preventing observations of LIDAR attenuated backscatter below such a layer [10]. For this case, we have chosen noncloud data to reduce this defect. Second, the daytime attenuated backscatter coefficient has low signal-to-noise ratio (SNR), especially for the spaceborne Lidar CALIOP. We used horizontally averaged (over $17 \mathrm{~km}$ [6]) CALIPSO attenuated backscatter coefficient profiles to increase SNR.

\section{A Case Study}

3.1. Regional Background. China has known a very rapid economic growth since the economic reforms began in 1978, resulting in a strong increase in energy consumption affecting air pollution and associated health effects. In China, large emissions are concentrated in the megacity clusters, such as Beijing-Tianjin-Hebei (BTH), the Pearl River delta (PRD), and the Yangtze River delta (YRD) regions [13, 14]. In our study, we have chosen Jinhua Basin as study area. Jinhua $\left(29.0^{\circ} \mathrm{N}, 119.5^{\circ} \mathrm{E}\right)$ is located in the Yangtze River delta region of East China, in the middle of Zhejiang province. The climate of Jinhua belongs to subtropical monsoon climate. Jinhua is in the hilly basin of middle of Zhejiang and topography of the north-south high, middle low.

From December 15, 2013, to June 7, 2014, a groundbased particle optical property observation experiment was carried on Jinhua, including sun photometer, Lidar, particulate matter in situ monitor consumers spectrometer and automatic weather station, and so on, aiming to get typical winter surface aerosol properties in the Yangtze River delta. During this period, 2 coincident times could be derived for CALIPSO, 13:26 PM, December 24, 2013, and 2:02 AM, December 27, 2013 (local time). In this study, we have selected the daytime case, 13:26 PM, December 24, 2013, to analyze because atmospheric movement is a strenuous activity during the daytime.

Figure 1 is Geostationary Ocean Color Imager (GOCI) image of Jinhua area on December 24, 2013, 12:16 PM. It is clear that the gray area presents high levels pollution. CALIPSO pass-across is shown in red line. This line was well going through the contaminated area. The blue dot indicates 


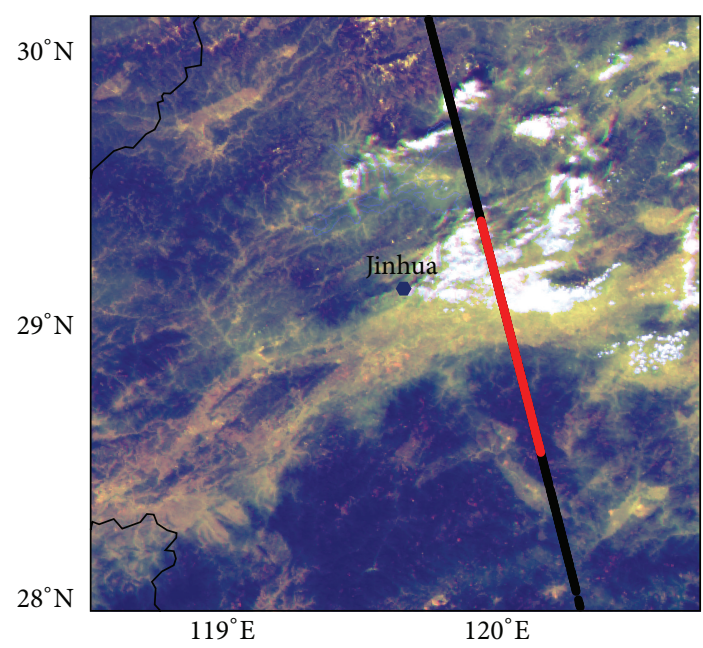

FIgURE 1: GOCI image of Jinhua area.

Jinhua, the ground-based observation site. One can observe such a pollution distribution because the area is surrounded by mountains, which prevents an efficient cleaning of the atmosphere through the transport of particles. This transport is furthermore known slower in winter.

In Figure 1, white area is cloud mask. We can clearly see that half of the orbit is cloud contamination in the Jinhua Basin. Although clouds exist, it can be seen clearly that the light gray area mainly came from the aerosol particles extinctions in Figure 1. However, Figure 2 showed that there is little cloud on the CALIPSO pass-across at 13:00, seeing removed clouds in the blue vertical lines.

3.2. Spatial Distribution of Backscatter Coefficient. Figure 2(a) is the altitude-orbit cross section of attenuated backscatter at $532 \mathrm{~nm}$ with respective PBLH and visibility level 13:26 PM, December 24, 2013, at Jinhua. The coincidental spot on $\left(29.2^{\circ} \mathrm{N}, 119.9^{\circ} \mathrm{E}\right) \mathrm{CALIPSO}$ pass-across was in the distance of about $32 \mathrm{~km}$ with the ground-based site, and Figure 2(a) displayed part of the orbit across about $1^{\circ} \mathrm{N}, \sim 100 \mathrm{~km}$ in about 5 mins. We consider that atmosphere structure slightly changes during that time. Attenuated backscatter could similarly express the concentration of atmospheric aerosol particles. The black line represents PBLH. Due to the effect of warm cover of the inversion layer, most of atmospheric aerosol particles concentrate in planetary boundary layer. Hence, between planetary boundary layer and free atmosphere, the concentration of atmospheric aerosol particles will change sharply [15-19]. In Figure 2(a), in most cases, green-yellow-orange colored features are aerosols, and redgray-white colored features are clouds [20], except for optically thick aerosol layers and optically thin clouds, especially cirrus $[19,20]$. It can be seen, in Figure 2(a), that largest backscatter coefficient from aerosol mainly occurs at the altitude about $1 \mathrm{~km}$, showed by the yellow-orange color. The black-gray color at $1 \mathrm{~km}$ may be thick aerosols, for main clouds have been removed, seeing the blue vertical lines. However, the thinnest ones could still remain. Near the surface, some yellow color shows the aerosols, which has a little bit backscatter coefficient intensity. Above the PBL, the region where aerosols mainly gathered is at the altitude of 1.8$3.5 \mathrm{~km}$.

In order to discuss the level of pollution, here pollution level is classified by visibility. We used aerosol optical depth (AOD) from CALIPSO L2 data and PBLH introduced above to deduce visibility $[17,18]$, considering that there is no extinction coefficient data available on CALIPSO products. We classify the visibility using an index: 1 corresponds to severe haze day, with visibility lower than $2 \mathrm{~km} ; 2$ corresponds to heavy haze day, with visibility range in $2-3 \mathrm{~km}$; range in $3-5 \mathrm{~km}$ corresponds to mild haze day, index to be 3 ; and $5-10 \mathrm{~km}$ indicates mild haze day, index to be 4 ; index 5 indicates clear day, with visibility higher than $10 \mathrm{~km}$. With these criteria, this study case is classified mostly as mild haze day (seeing in Figure 2(b)). The spatial distribution could be well illustrated here, with the higher visibility around the basin and lower visibility in the middle. However, two things should be noted here. First, for the strong backscatter coefficient by the surface, it is difficult to obtain surface backscatter coefficient to induce visibility. Second, AOD from CALIPSO should be lower than AOD from ground-based observation [21], which means the real visibility should be lower than that we estimated. Pollution levels should be worse than estimated.

In order to show the case of accumulated backscatter coefficient in the vertical direction, we discussed vertical distribution of the attenuated backscatter in Figure 3. Based on L2-333 data, we picked no cloud backscatter profiles and averaged. The average elevation in study region is $258 \mathrm{~m}$, so we set $0.1 \mathrm{~km}$ (Figure 3(a)), $0.3 \mathrm{~km}$ (Figure 3(b)), and $0.5 \mathrm{~km}$ (Figure 3(c)) as different elevation classifications. For visibility ranging in $0-30 \mathrm{~km}$, we set $3-5 \mathrm{~km}$ (green line), $5-10 \mathrm{~km}$ (red line), and larger than $10 \mathrm{~km}$ (black line) as different visibility classifications. Table 1 shows the details of the elevation range in attenuated backscatter coefficient profile selection.

Generally, there are two small backscatter coefficient peaks and one backscatter coefficient region in each profile from the bottom up, at around $0.3,1.0$, and $1.8-3.5 \mathrm{~km}$. In Figure 3, horizontal line indicates the peak height, with purple horizontal line (first peak), blue horizontal line (second peak), and orange dotted line area in around $1.8-3.5 \mathrm{~km}$ (third region) from the bottom to up. The first and second peaks are under PBLH (black horizontal line). In cases of 0.3 and $0.5 \mathrm{~km}$ surface elevation, the first peak heights nearly were about $0.4 \mathrm{~km}$ higher than the $0.1 \mathrm{~km}$ cases. The third region in around $1.8-3.5 \mathrm{~km}$ indicated aerosol accumulation upon the PBLH (though it looks to be of lighter color than that under the PBLH). Usually the aerosol upon the PBLH is much less than that under the PBL. It mainly comes from two parts. One is escaped from the inner of PBL; the other is transfer from other places. Besides, at different elevation, the height of the peak varies: the higher the elevation, the higher the height of each aerosol layer. It illustrated that, in the basin, the pollution layer would be kept lower in middle than around side.

The value of attenuated backscatter coefficient ranged sequentially with visibility, first with visibility more than 


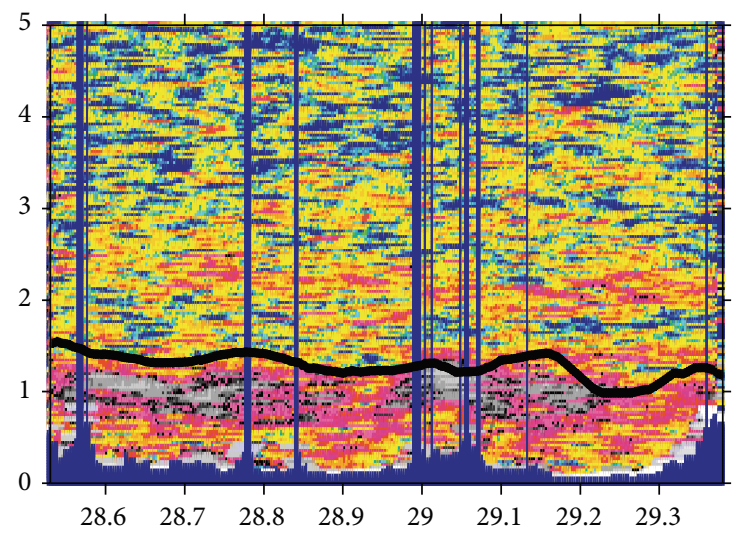

(a)

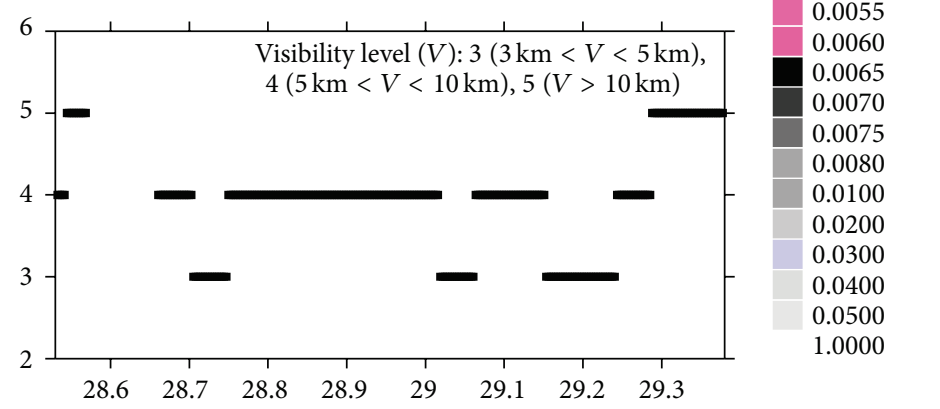

(b)

FIGURE 2: The altitude-orbit cross section of attenuated backscatter at $532 \mathrm{~nm}$ and accordingly PBLH, visibility level at 13:00 (local time), December 24, 2013 (Figure 2(a) gave the altitude-orbit cross section of attenuated backscatter at $532 \mathrm{~nm}$ with respective PBLH and visibility level 13:26 PM, December 24, 2013, at Jinhua). Blue region in the bottom represents surface height, and pink-yellow-gray colors show the different degrees of aerosol extinction. The black line in Figure 2(b) is the horizontal visibility along the orbit. Visibility level is defined as follows: level 3 indicates the visibility range in $3-5 \mathrm{~km}$, level 4 indicates the visibility between 5 and $10 \mathrm{~km}$, and level 5 indicates the visibility larger than $10 \mathrm{~km}$.

TABLE 1: Elevation range in attenuated backscatter coefficient profile selection.

\begin{tabular}{|c|c|c|c|c|c|c|c|c|c|}
\hline Visibility level/elevation level $(\mathrm{km})$ & $5 / 0.1$ & $4 / 0.1$ & $3 / 0.1$ & $5 / 0.3$ & $4 / 0.3$ & $3 / 0.3$ & $5 / 0.5$ & $4 / 0.5$ & $3 / 0.5$ \\
\hline Range of selected elevation $(\mathrm{km})$ & $0.082-0.113$ & 0.113 & $0.53-0.113$ & 0.292 & 0.322 & $0.292-0.322$ & $0.473-0.532$ & $0.502-0.532$ & $0.472-0.502$ \\
\hline
\end{tabular}

$10 \mathrm{~km}$ and second with visibility between $5 \mathrm{~km}$ and $10 \mathrm{~km}$ and followed by the one with visibility range in 3$5 \mathrm{~km}$. The backscatter is largest near the surface at most $0.6 \mathrm{~km}^{-1} \mathrm{sr}^{-1}$, followed by the value around $1 \mathrm{~km}$ about 0.006 to $0.01 \mathrm{~km}^{-1} \mathrm{sr}^{-1}$. It illustrated that the serious pollution happened near the surface and another pollution layer at PBLH. And a clear layer at $0.3 \mathrm{~km}$ still can be seen clearly in Figure 3 .

3.3. Temporal Distribution of Backscatter Coefficient. The study of the temporal distribution of aerosol relies on the analysis of the ground-based Lidar observations. The attenuated backscatter Lidar image for December 24, 2014 (local time), is shown in Figure 4. Blue color indicates low backscattering levels (mainly molecules), while light bluered-yellow colors show more dense areas (aerosols). Most of aerosol backscatter coefficient is under the PBLH. From 10:00 oclock, the red color became darker. It showed that pollution was becoming worse and PBLH became higher from $1 \mathrm{~km}$ to $1.5 \mathrm{~km}$. This is a normal characteristic of the planetary boundary layer and daytime solar activity provides them with energy.

In Figure 4, aerosol backscatter coefficient mainly concentrated under the PBL; backscatter intensity near surface is lower than that near the boundary. And above the PBL, there are some light backscatter characteristics at $2 \mathrm{~km}$ to $3 \mathrm{~km}$ during 0:00-4:00 and at around $2 \mathrm{~km}$ during 13:0017:00. This aerosol vertical distribution just agrees with the analysis of spaceborne case. Above $2.5 \mathrm{~km}$, there is also some noise which should be neglected.

The in situ measurement was showed in Figure 5, including AOD, surface extinction, wind speed, temperature, and 


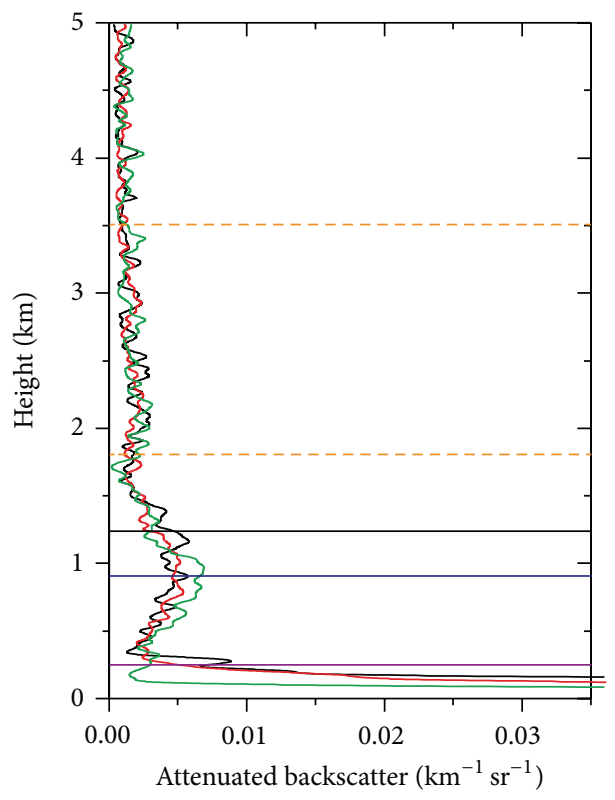

Classification of visibility

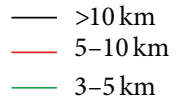

Elevation: $0.1 \mathrm{~km}$

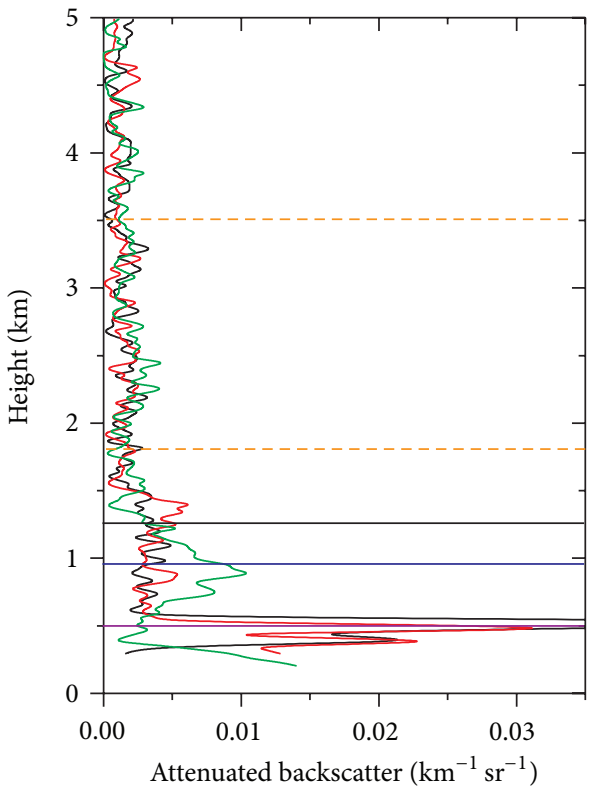

Classification of visibility

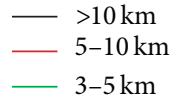

Elevation: $0.3 \mathrm{~km}$

(b)

(a)

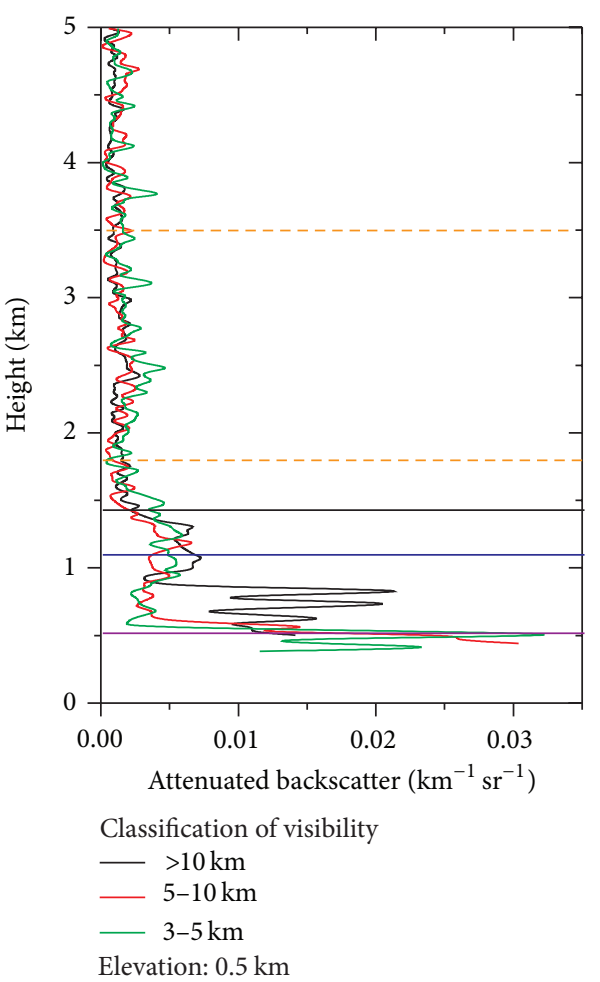

(c)

FIgURE 3: Vertical distribution of attenuated backscatter, classified based on elevation and visibility (above sea level). 


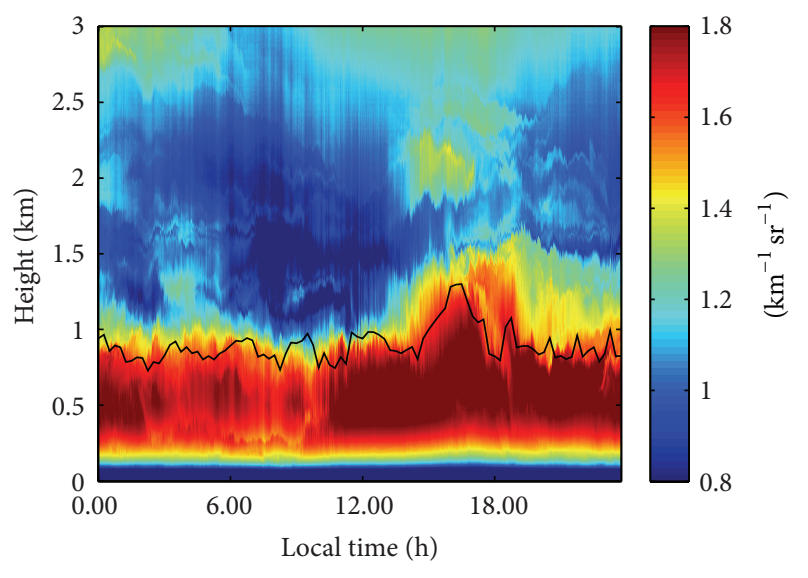

FIGURE 4: Attenuated backscatter coefficient image of ground-based Lidar on December 24, 2013.

relative humidity. AOD and surface extinction have a good consistency from 14:00 to 16:00 (seeing Figure 5(a)). And the trend of surface extinction is consistent with relative humidity and is opposite to temperature (Figures 5(b) and 5(c)). In this period, the wind speed is always low, about 0.3 to $3.8 \mathrm{~m} / \mathrm{s}$ (Figure 5(b)). It seems that high humidity, low temperature, and wind speed may be the typical characteristics of the pollution in this area.

3.4. Trajectories Analysis. The above discussion was focused on the main characteristics of the aerosol extinction vertical distribution. In this part, we focus on the different sources in different layers. In Figure 6, back trajectories with a period of 24 hours using HYSPLIT model were depicted at $0.3 \mathrm{~km}$ (blue), $1.0 \mathrm{~km}$ (green), and $2.0 \mathrm{~km}$ (red) above ground level in order to detect possible links pathway of particles transported toward Jinhua area. The triangles in Figure 6(a) correspond to ground-based observation time, purple to 0:00 AM December 24, gray to 13:00 PM, and yellow to 0:00 AM December 25. In Figure 6(b), the black line corresponds to the CALIPSO pass-across. The red line shows that the source of air mass at $2.0 \mathrm{~km}$ is different from the other two layers. Aerosols below $0.3 \mathrm{~km}$ mainly come from local sources, and haze is probably caused by two reasons. First, with industrial development, substantial increase of pollutant emissions and urban suspended solids (e.g., from motor vehicles) can lead to a direct result of reduced visibility, making hazy conditions. Second, wind speed in winter in the basin is low, the highest up to $3 \mathrm{~m} / \mathrm{s}$ in Figure 5(b). It is not conducive to the dilution and degradation of air pollutants in urban area, and these pollutants can easily accumulate up to a high concentration above the basin.

In Figure 6(a), the direction and distance of air mass in $0.3 \mathrm{~km}$ layer changed slowly compared with those in $1.0 \mathrm{~km}$ and $2.0 \mathrm{~km}$ layer through 24 hours. That caused pollution near the surface hard to spread over a wide area in a short time. In Figure 6(b), the direction and distance of air mass in three layers, respectively, were across $\sim 100 \mathrm{~km}$ in $5 \mathrm{mins}$. It can be inferred that the source of pollution is nearly the same at the same layers in $\sim 100 \mathrm{~km}^{2}$ district at the same time.

\section{Discussions}

We did a comparison of PBLH obtained from ground-based Lidar observation and spaceborne CALIPSO. In order to homogenize processes and focus on instrumental differences, we deal with these two kinds of data with the same methods: the standard deviation method and the Haar wavelet technique.

Ground-based Lidar observations from May 2013 to December 2013 are selected in this study. Due to the wellmixed atmosphere inside the boundary layer at about 13:00, it is easier to obtain planetary boundary layer during daytime [6]. We focus on this period for the following comparison, which sums up 5 sample points. Comparative results show that PBLH from ground-based Lidar is systemically lower than that from spaceborne Lidar (about $193 \mathrm{~m}$ ) seeing Figure 7. During some days of the error over $200 \mathrm{~m}$, the main consideration of the ground-based Lidar beam sometimes cannot reach the top of the PBL if the aerosol layer is dense or if there are some clouds. From this result, PBLH from CALIPSO could be used to analyze pollution in this case study.

\section{Conclusions}

Air pollution near the ground is closely related with the terrain; the high elevation would take advantage of the spread of contamination. The structure of pollution layer of the high elevation seems to be the same as the low elevation. A small difference is that the height of pollution layer will be higher, and it is easier to dissipate pollution.

In this study, we calculated PBLH from different Lidar data source, ground-based and spaceborne. Combining the in situ measurement and the HYSPLIT model, a haze case on December 24, 2013, was analyzed. Vertically, with the reduced height, backscatter increased and air pollution became serious. Under the PBL, the strong temperature inversion and descending air motions in the planetary boundary layer (PBL) allowed pollutants to accumulate at about $1 \mathrm{~km}$. This shallow layer appears to be stable and prevents the spread of contamination in the middle of basin. And these aerosols mainly come from Jiangsu province in north of Jinhua Basin. At the height of $0.3 \mathrm{~km}$, there is a clear layer, which divided the aerosol into two parts within PBL. Under $0.3 \mathrm{~km}$, the aerosol is local products and mostly gathered in the middle of Jinhua Basin. Above the PBL, the characteristics of aerosol seem not to be the same as that under PBL. They mainly come from two sources: first, little aerosol is transported up to PBL helped by wind shear; second, part of aerosol comes from long distance transportation and may come from the west of China, which will continue to be studied in the future.

One case study is faraway from understanding all conditions of haze formation. As part of ongoing work, we plan to undertake more typical climatic characteristic case, such as 


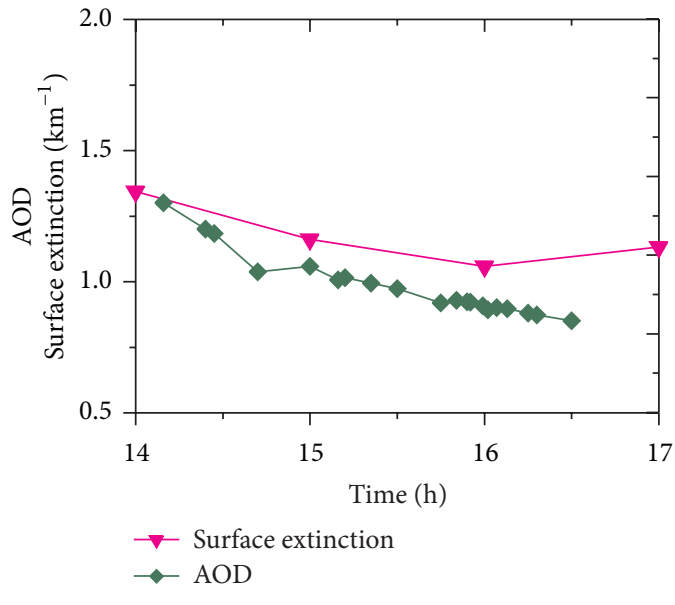

(a)

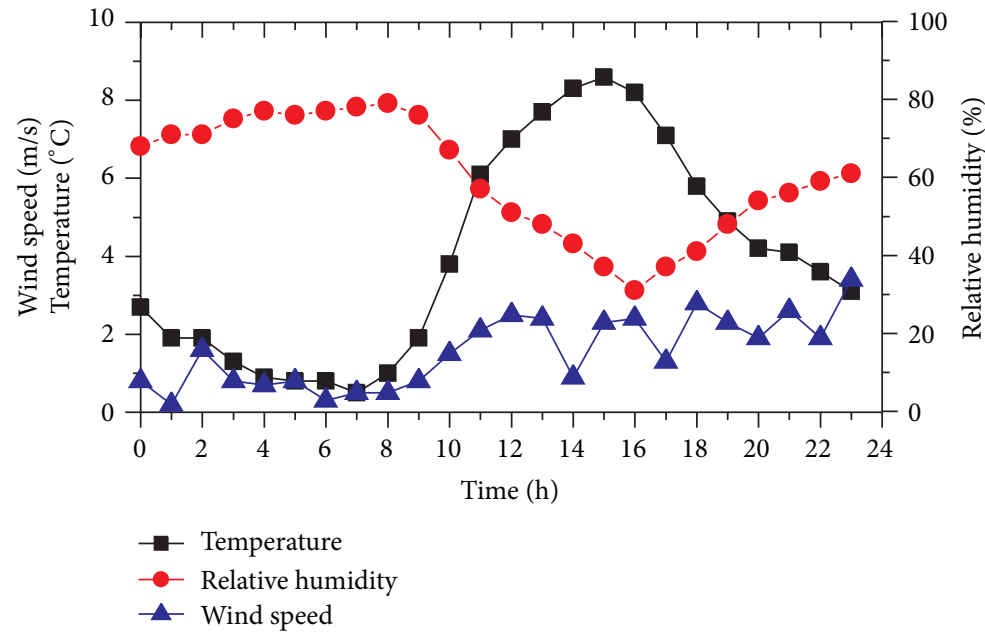

(b)

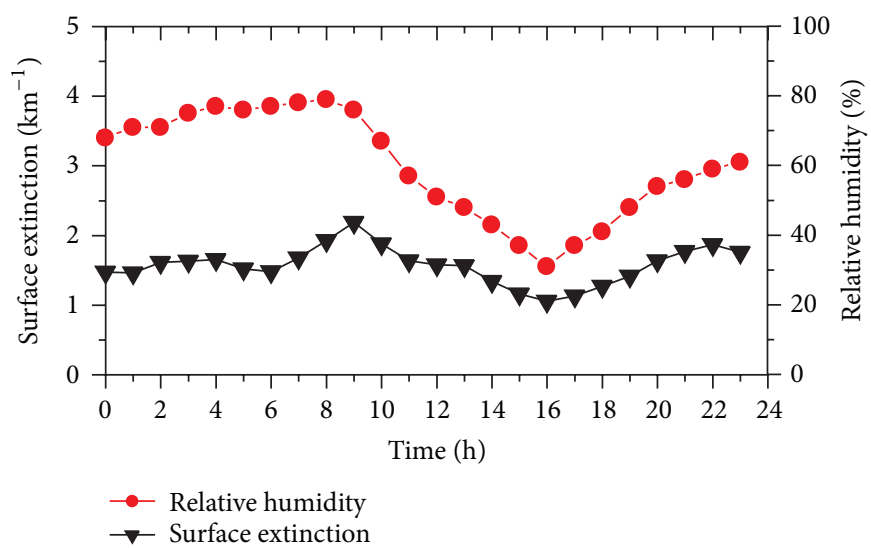

(c)

FIGURE 5: In situ measurement (AOD, surface extinction, wind speed, temperature, and relative humidity) on December 24, 2013.

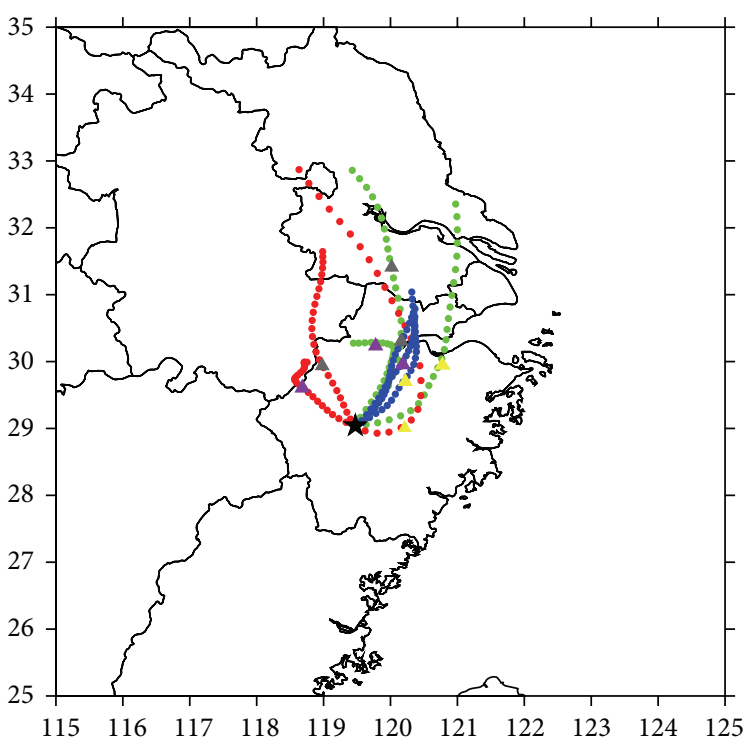

(a)

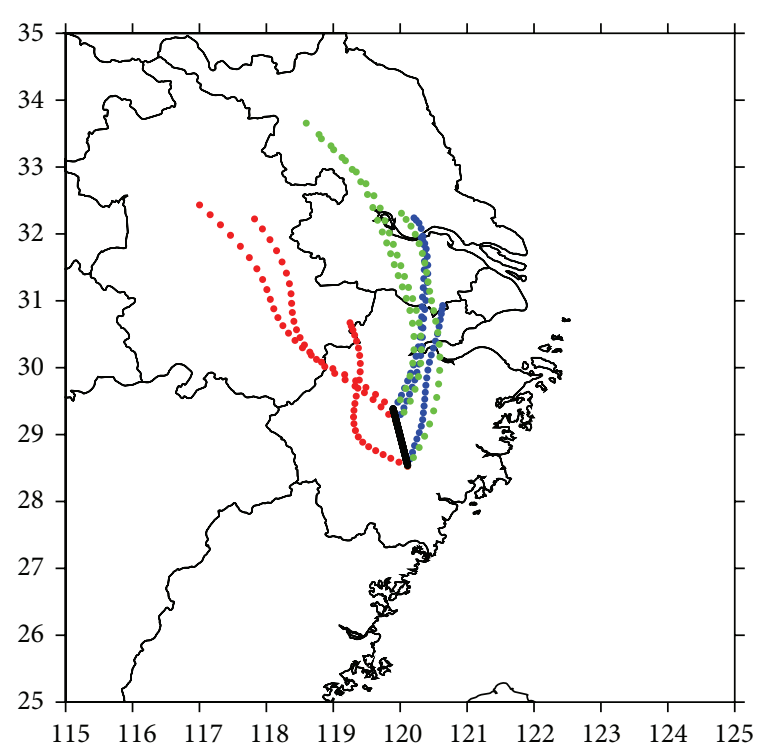

(b)

FIGURE 6: 24-hour back trajectories using the HYSPLIT model at $0.3 \mathrm{~km}$ (blue), $1.0 \mathrm{~km}$ (green), and $2.0 \mathrm{~km}$ (red) above ground level: (a) ground-based and (b) CALIPSO. 


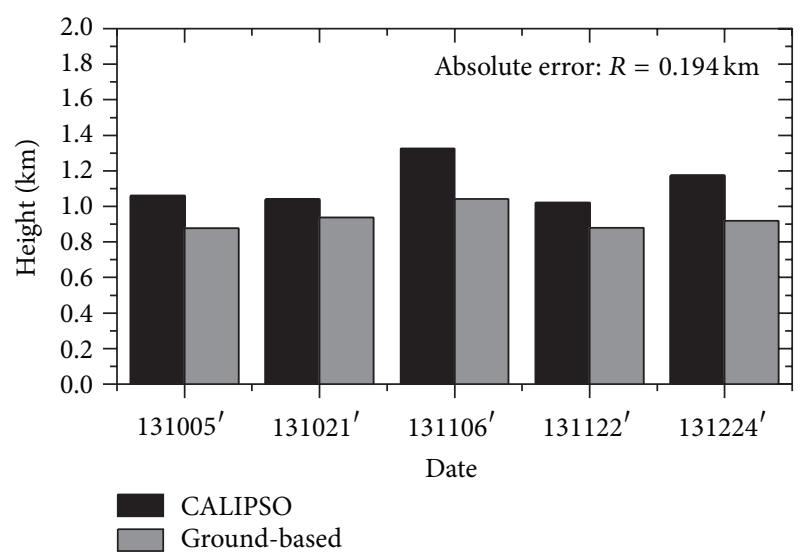

FIGURE 7: Comparison of PBLH result from CALIPSO and groundbased Lidar observation.

Beijing, Lanzhou, in order to gain a deeper understanding of the formation of pollution.

\section{Conflict of Interests}

The authors declare that there is no conflict of interests regarding the publication of this paper.

\section{Acknowledgments}

The Jinhua Observation Experiment got the support of Dr. Jie Shao and others from Zhejiang Normal University. And the authors acknowledge the support of the Strategic Priority Research Program-Climate Change: Carbon Budget and Relevant Issues of the Chinese Academy of Sciences (no. XDA05100202) and the Chinese Academy of Sciences Key Deployment Project (no. KZZD-EW-TZ-18).

\section{References}

[1] S. Groß, M. Esselborn, M. Wirth, A. Fix, and A. Minikin, "Airborne high spectral resolution lidar observation of pollution aerosol during EUCAARI-LONGREX," Atmospheric Chemistry and Physics, vol. 13, no. 5, pp. 2435-2444, 2013.

[2] P. Forster, V. Ramaswamy, P. Artaxo et al., Climate Change 2007. The Physical Science Basis, Changes in Atmospheric Constituents and in Radiative Forcing, Intergovernmental Panel on Climate Change, 2007.

[3] F. T. Stocker, D. Qin, K. G. Plattner et al., Climate Change 2013: The Physical Science Basis. Working Group I Contribution to the Fifth Assessment Report of the Intergovernmental Panel on Climate Change, Summary for Policymakers, IPCC, 2013.

[4] Z. Li, X. Gu, L. Wang et al., "Aerosol physical and chemical properties retrieved from ground-based remote sensing measurements during heavy haze days in Beijing winter," Atmospheric Chemistry and Physics, vol. 13, no. 2, pp. 10171-10183, 2013.

[5] A. Mortier, P. Goloub, T. Podvin et al., "Detection and characterization of volcanic ash plumes over Lille during the
Eyjafjallajökull eruption," Atmospheric Chemistry and Physics, vol. 13, no. 7, pp. 3075-3720, 2013.

[6] E. L. McGrath-Spangler and A. S. Denning, "Estimates of North American summertime planetary boundary layer depths derived from space-borne lidar," Journal of Geophysical Research D: Atmospheres, vol. 117, no. 15, Article ID D15101, 2012.

[7] D. J. Seidel, C. O. Ao, and K. Li, "Estimating climatological planetary boundary layer heights from radiosonde observations: comparison of methods and uncertainty analysis," Journal of Geophysical Research D: Atmospheres, vol. 115, no. 16, Article ID D16113, 2010.

[8] S. Emeis, K. Schäfer, and C. Münkel, "Surface-based remote sensing of the mixing-layer height-a review," Meteorologische Zeitschrift, vol. 17, no. 5, pp. 621-630, 2008.

[9] D. M. Winker, W. H. Hunt, and M. J. McGill, "Initial performance assessment of CALIOP," Geophysical Research Letters, vol. 34, no. 19, Article ID L19803, 2007.

[10] S. H. Melfi, J. D. Spinhirne, S.-H. Chou, and S. P. Palm, "Lidar observations of vertically organized convection in the planetary boundary layer over the ocean," Journal of Climate \& Applied Meteorology, vol. 24, no. 8, pp. 806-821, 1985.

[11] N. S. Jordan, R. M. Hoff, and J. T. Bacmeister, "Validation of Goddard Earth Observing System-version 5 MERRA planetary boundary layer heights using CALIPSO," Journal of Geophysical Research D: Atmospheres, vol. 115, no. 24, Article ID D24218, 2010.

[12] E. L. McGrath-Spangler and A. S. Denning, "Global seasonal variations of midday planetary boundary layer depth from CALIPSO space-borne LIDAR," Journal of Geophysical Research D: Atmospheres, vol. 118, no. 3, pp. 1226-1233, 2013.

[13] X. J. Zhao, P. S. Zhao, J. Xu et al., "Analysis of a winter regional haze event and its formation mechanism in the North China Plain," Atmospheric Chemistry and Physics, vol. 13, no. 11, pp. 5685-5696, 2013.

[14] D. D. Parrish and T. Zhu, "Clean Air for Megacities," Science, vol. 326, no. 5953, pp. 674-675, 2009.

[15] W. Zhang, Y. Zhang, Y. Lv, K. Li, and Z. Li, "Observation of atmospheric boundary layer height by ground-based LiDAR during haze days," Journal of Remote Sensing, vol. 17, no. 4, pp. 981-992, 2013.

[16] A. Lammert and J. Bösenberg, "Determination of the convective boundary-layer height with laser remote sensing," BoundaryLayer Meteorology, vol. 119, no. 1, pp. 159-170, 2006.

[17] D. Liu, Development of polarization-Mie lidar and lidar observation of atmosphere boundary layer [Ph.D. dissertation], Hefei Institutes of Physical Science, 2005.

[18] D. Bäumer, B. Vogel, S. Versick, R. Rinke, O. Möhler, and M. Schnaiter, "Relationship of visibility, aerosol optical thickness and aerosol size distribution in an ageing air mass over SouthWest Germany," Atmospheric Environment, vol. 42, no. 6, pp. 989-998, 2008.

[19] Y. Chen, Q. Liu, F. Geng et al., "Vertical distribution of optical and micro-physical properties of ambient aerosols during dry haze periods in Shanghai," Atmospheric Environment, vol. 50, pp. 50-59, 2012.

[20] Z. Liu, D. Liu, J. Huang et al., "Airborne dust distributions over the Tibetan Plateau and surrounding areas derived from the first year of CALIPSO lidar observations," Atmospheric Chemistry and Physics, vol. 8, no. 16, pp. 5045-5060, 2008.

[21] A. H. Omar, D. M. Winker, J. L. Tackett et al., "CALIPSO AERONET aerosol optical depth intercomparisons: one size fits none," in Proceedings of the American Geophysical Union Fall Meeting, 2011, abstract \#A43A-0126. 

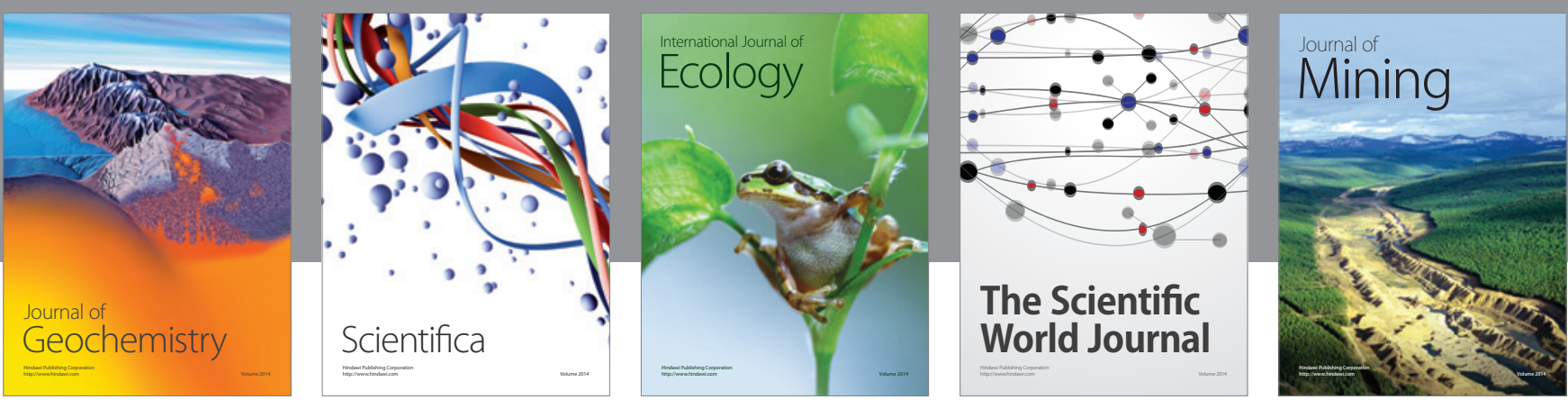

The Scientific World Journal
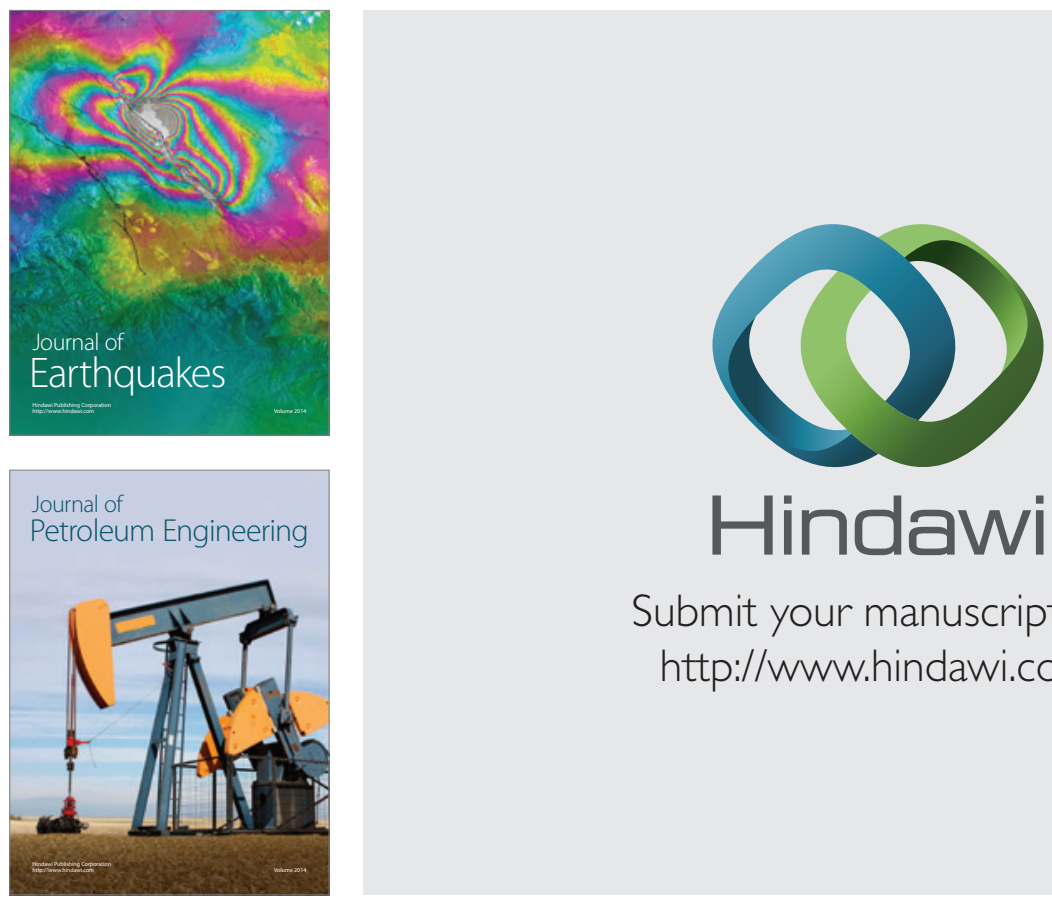

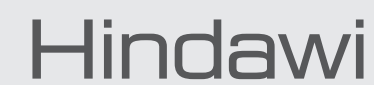

Submit your manuscripts at

http://www.hindawi.com
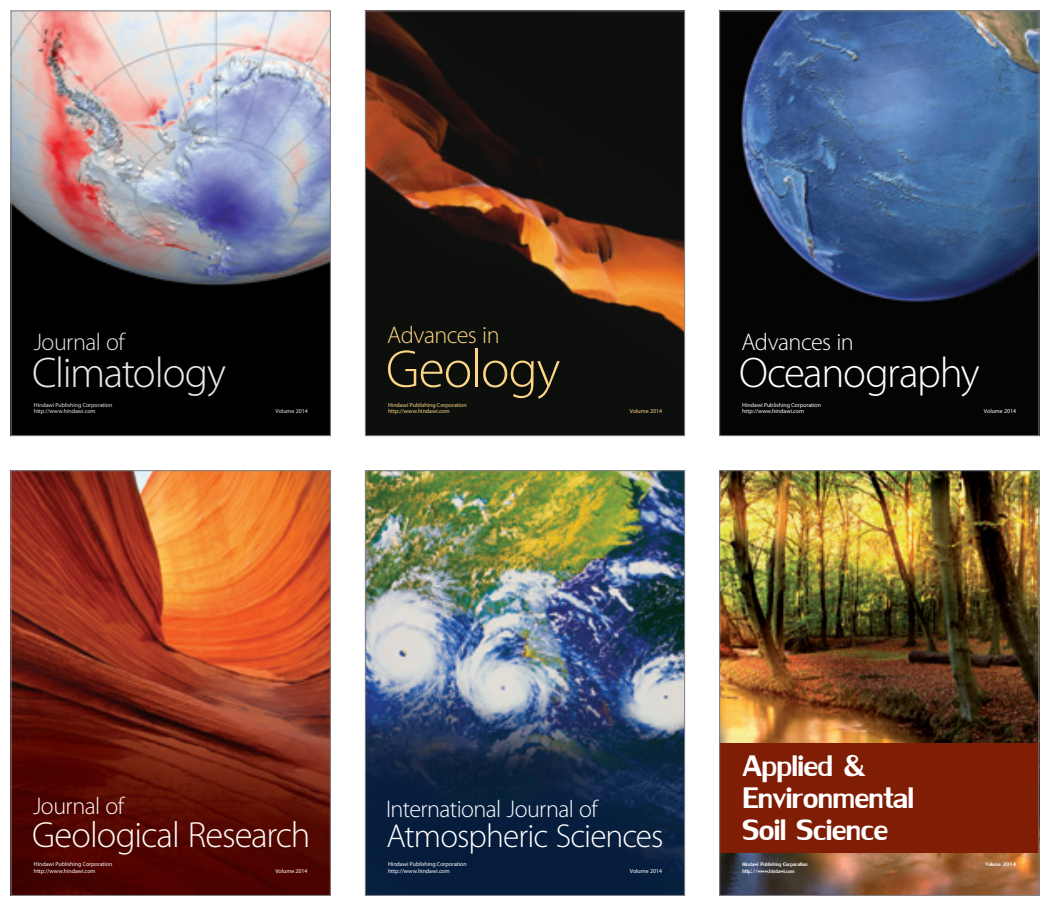
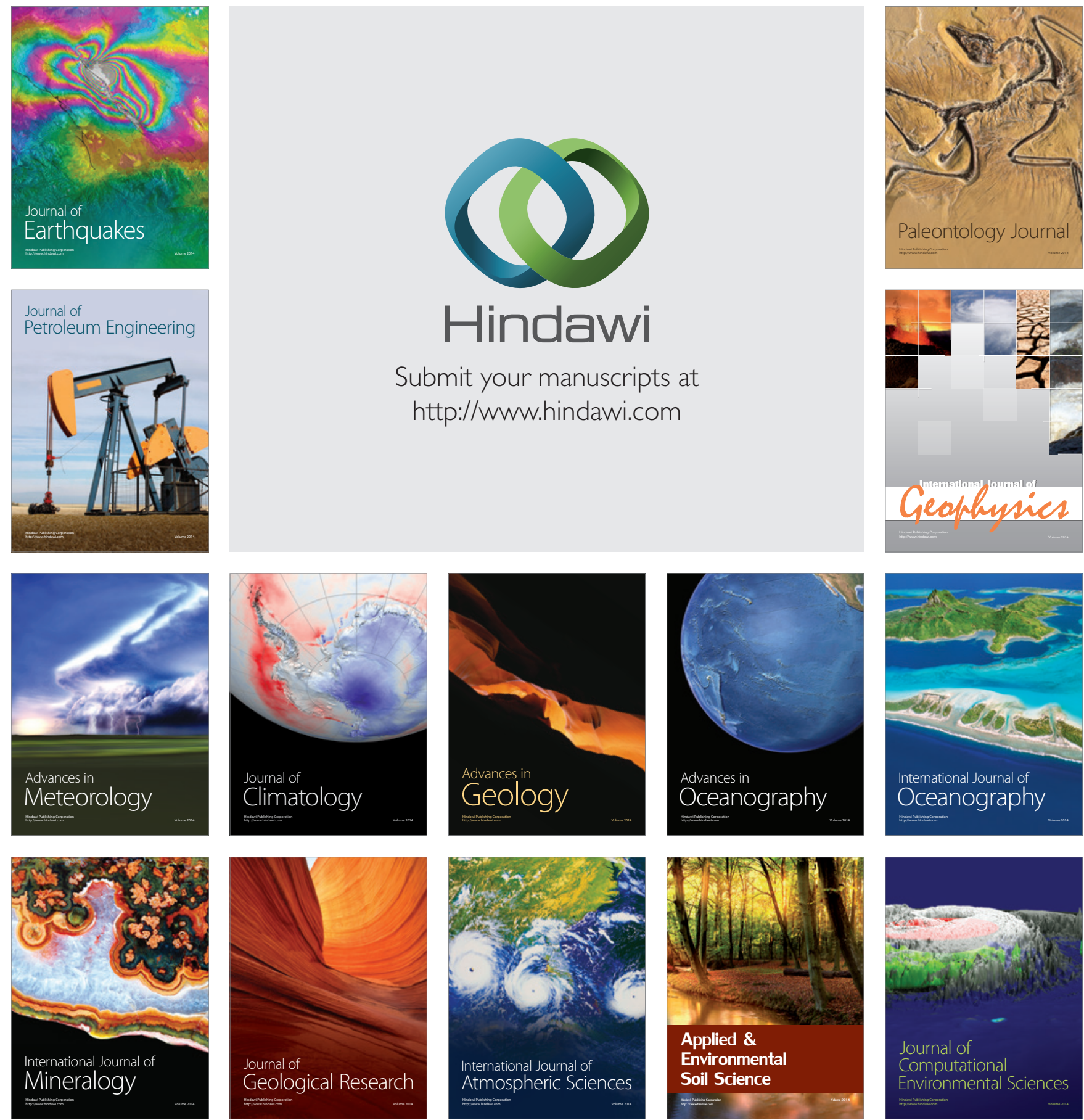